\title{
The clinical epidemiology of male osteoporosis: a review of the recent literature
}

This article was published in the following Dove Press journal:

Clinical Epidemiology

9 January 2015

Number of times this article has been viewed

\author{
Tina Willson ${ }^{1,2}$ \\ Scott D Nelson ${ }^{1,2}$ \\ Jonathan Newbold' \\ Richard E Nelson ${ }^{2,3}$ \\ Joanne LaFleur ${ }^{1,2}$ \\ 'University of Utah College of \\ Pharmacy, ${ }^{2}$ Veterans Affairs Salt Lake \\ City Health Care System, ${ }^{3}$ University \\ of Utah School of Medicine, Salt Lake \\ City, UT, USA
}

\begin{abstract}
Osteoporosis, a musculoskeletal disease characterized by decreased bone mineral density (BMD) and an increased risk of fragility fractures, is now recognized as an important public health problem in men. Osteoporotic fractures, particularly of the hip, result in significant morbidity and mortality in men and lead to considerable societal costs. Many national and international organizations now address screening and treatment for men in their osteoporosis clinical guidelines. However, male osteoporosis remains largely underdiagnosed and undertreated. The objective of this paper is to provide an overview of recent findings in male osteoporosis, including pathophysiology, epidemiology, and incidence and burden of fracture, and discuss current knowledge about the evaluation and treatment of osteoporosis in males. In particular, clinical practice guidelines, fracture risk assessment, and evidence of treatment effectiveness in men are addressed.
\end{abstract}

Keywords: screening, treatment, fracture risk, guidelines, diagnosis

\section{Introduction}

Osteoporosis is a musculoskeletal disease characterized by decreased bone mineral density (BMD) and increased risk of fragility fractures. Osteoporosis is a silent disease with no symptoms until a fracture occurs. Osteoporotic fractures result in significant mortality and morbidity in men and lead to considerable societal costs, including direct medical costs and indirect costs resulting from reduced quality of life, disability, and death. ${ }^{1}$

Typically thought of as a disease impacting women, increasing attention is being paid to osteoporosis in males. As many as one in four men over the age of 50 years will develop at least one osteoporosis-related fracture in their lifetime. . $^{2,3}$ In 2005 , men accounted for $29 \%$ of the 2 million osteoporotic fractures in the US and $25 \%$ of the associated US\$17 billion in costs. ${ }^{4}$ Of all osteoporotic fractures, hip fractures contribute to the greatest morbidity and mortality in men. Each year, about 80,000 men will break their hip; ${ }^{2}$ of these, one in three will die in the first year after a hip fracture and another one-third will fracture again. ${ }^{5}$ In light of these statistics, male osteoporosis is recognized as a growing public health concern and many clinical guidelines now address the evaluation and treatment of osteoporosis in males. Despite this guidance, male osteoporosis remains an underdiagnosed and undertreated condition.

The aims of this narrative review are to present a brief overview of osteoporosis in men and discuss current knowledge about the evaluation and treatment of osteoporosis in males. We searched PubMed for studies related to male osteoporosis with
Correspondence: Tina Willson Pharmacotherapy Outcomes Research Center, University of Utah, 30 South 2000 East, Salt Lake City, UT, USA Email tina.willson@utah.edu 
a focus on those published from 2003-2013. We used the reference list of these articles to obtain additional sources. The review begins with a brief description of bone development and loss in males and the causes and diagnosis of male osteoporosis. We continue with a discussion of the prevalence of osteoporosis and incidence of fracture in males and the resulting burden on the health care system and society. Finally, we address clinical practice guidelines, fracture risk assessment, and the evidence of treatment effectiveness in men.

\section{Disease etiology and pathophysiology Bone development}

Important differences exist between men and women with regards to bone development and loss. Early in life, bone development is influenced by many factors, such as sex hormones, physical activity level, and body size, with puberty possibly having the greatest effect on bone formation and development in both men and women. Typically, men start puberty later in life and continue in puberty longer than women, which can cause differences in bone development between males and females. For example, men tend to have longer legs than women, because epiphyseal fusion (which limits bone growth) occurs later, so men tend to have a longer bone maturation period..$^{6-8}$ Sex hormones also have a significant effect on bone growth and the amount of bone tissue present at the end of bone maturation. ${ }^{9}$ In men, testosterone during puberty leads to the development of larger skeletons, whereas estrogen does not. ${ }^{10}$ As for bone density, estrogens typically reduce bone resorption, thereby conserving bone mass. Testosterone can also reduce bone resorption; however, this effect may be due to the conversion of testosterone into estrogens. Testosterone also has a modest effect on enhancing bone tissue formation. ${ }^{11}$ In other words, estrogens conserve bone mass, while testosterone may increase bone mass. By young adulthood, most men have developed various advantages that protect their bones from fragility fractures compared to women, such as a higher peak bone mass, larger bone size, and greater bone strength. ${ }^{7,12}$

In childhood development, obese adolescent males are more likely to have larger and stronger bones in the forearms and lower legs compared to their normal-weight peers. ${ }^{13}$ However, a subset of the Childhood Health, Activity, and Motor Performance School (CHAMPS) study in Denmark, showed a positive relationship between a moderate-to-high level of physical activity and bone mineral content, BMD accumulation, and bone area in childhood. ${ }^{14}$ Overall, these studies suggest that mechanical load, through extra body weight or physical activity, influences bone development in childhood and adolescence.

\section{Bone loss}

While both men and women lose bone mass during aging, there are important differences that result in a lower fracture risk for men. ${ }^{7}$ As with bone formation, the sex steroids have important roles in bone loss through aging. In women, the decrease in estrogen due to menopause causes bone resorption to increase by $90 \%$ while bone formation increases by only $45 \%$, leading to overall bone loss. However, men have a more gradual decrease in sex steroid levels with aging, which may account for the less severe decrease in bone strength. ${ }^{10}$

Differences also exist in the way in which bone remodeling occurs in men and women. In women, more mineralized bone is replaced by less mineralized bone. Additionally, the trabecular surface, which is the area over which mechanical stresses can be distributed, decreases in women, resulting in microdamage due to increased stress on the bones. In men, as the trabecular surface decreases, there is an increase in bone formation..$^{15}$ Overall, the result is a smaller decline in BMD in men than in post-menopausal women, and it appears that the advantages to the male bones in early life continue into the later decades of life. ${ }^{16}$

\section{Causes of male osteoporosis}

Male osteoporosis is typically classified into two different categories, primary and secondary osteoporosis. Types of primary male osteoporosis include age-related osteoporosis and idiopathic male osteoporosis. Age-related osteoporosis in men, like in women, is more likely to occur as age increases, and is typically seen in males over the age of 70 years. Idiopathic male osteoporosis, on the other hand, is generally defined as one or more fractures and a low BMD in men before the age of $65-70$ years old. ${ }^{17}$ There are multiple theories as to the etiology of idiopathic male osteoporosis, such as genetic factors or a familial history. Several epidemiological and clinical observations have shown that osteoporosis in both men and women has an important genetic component. Multiple genes have shown effects on bone development, strength, density, etc. ${ }^{18,19}$ A recent study showed that men whose fathers had osteoporosis tended to also have reduced bone size and reduced volumetric BMD. ${ }^{20}$ 
Male osteoporosis that can be linked to or explained by causes other than aging is generally classified as secondary male osteoporosis. Chronic diseases that have been associated with secondary osteoporosis are listed in Table 1 and include diseases such as chronic obstructive pulmonary disease (COPD), ${ }^{21,22}$ cardiovascular disease, ${ }^{23}$ rheumatoid arthritis, ${ }^{24}$ osteoarthritis, ${ }^{25}$ and multiple sclerosis. ${ }^{26,27}$ Other causes of secondary osteoporosis in men include alcohol abuse, glucocorticoid excess (exogenous or endogenous), and hypogonadism (idiopathic or through androgen deprivation therapy). ${ }^{28}$ Despite the higher prevalence of osteoporosis, osteopenia, and fractures in patients with these characteristics, testing and treatment rates are low. Some predictors of osteoporosis identification and treatment among US veterans include exposure to gonadotropin-releasing hormone (GnRH) analogs, prior fragility fractures, a history of falls, and a diagnosis of rheumatoid arthritis. ${ }^{29}$

\section{Diagnosis}

The clinical diagnosis of osteoporosis is made on the basis of the widely accepted bone BMD T-score criteria established by the World Health Organization (WHO). The WHO has defined four diagnostic categories: ${ }^{33}$

- Normal: T-score greater than -1.0 (BMD less than 1.0 standard deviation [SD] below that of a normal young adult);

Table I Secondary causes of male osteoporosis

\begin{tabular}{ll}
\hline Medications & Anticonvulsants \\
& Chemotherapeutics \\
& Glucocorticoids \\
& Thyroid hormone \\
Chronic diseases & COPD \\
& Gastrointestinal disorders: malabsorption \\
& syndromes, inflammatory bowel disease, celiac \\
& sprue, primary biliary cirrhosis, postgastrectomy, etc \\
& Hypercalciuria \\
& Hyperthyroidism \\
& Hyperparathyroidism \\
& Hypogonadism \\
& Neuromuscular disorders \\
& Systemic illnesses: mastocytosis, malignancies \\
& Rheumatoid arthritis \\
& Low serum levels of vitamin D \\
& Low calcium \\
Poor nutrition & Alcohol abuse \\
& Post-transplant osteoporosis \\
& Sedentary lifestyle \\
Other & Tobacco abuse \\
&
\end{tabular}

Note: Data from. . $830-32^{3}$

Abbreviation: COPD, chronic obstructive pulmonary disease.
- Osteopenia (low bone mass): T-score between -1.0 and -2.5 (BMD between 1.0 and 2.5 SDs below a young adult norm);

- Osteoporosis: T-score of -2.5 or lower (BMD of 2.5 or more SDs below that of a normal young adult);

- Severe or established osteoporosis: the same BMD criteria as osteoporosis, but in the presence of one or more fragility fractures.

The WHO thresholds were published in 1994 and developed for use in white postmenopausal women. The development of new technologies for measuring BMD and more skeletal sites available for assessment, along with an increased knowledge of osteoporosis in men has led to controversy about whether the WHO criteria are appropriate in men. ${ }^{34,35}$ While central dual-energy X-ray absorptiometry (DXA) screening is the preferred approach for assessing $\mathrm{BMD},{ }^{36}$ there has been disagreement about which skeletal sites should be used for BMD assessment and which referent population to use (male or female) when calculating T-scores for men.

Updated guidance from the WHO Collaborating Centre and the International Osteoporosis Foundation (IOF) designate the use of diagnostic thresholds in men aged 50 years and older and recommend BMD measurement using DXA at the femoral neck as the reference standard for diagnosing osteoporosis in men. ${ }^{35,37}$ The National Osteoporosis Guideline Group (NOGG) ${ }^{38}$ in the UK endorses the WHO and IOF recommendations. The US National Osteoporosis Foundation (NOF) ${ }^{39}$ and the Endocrine Society recommend the use of central DXA of the hip and spine for osteoporosis diagnosis, with the Endocrine Society recommending the use of the forearm ( $1 / 3$ radius) when spine or hip scans cannot be interpreted and for men with hyperparathyroidism or receiving androgen deprivation therapy for prostate cancer. ${ }^{40}$ Osteoporosis Canada bases diagnosis on the lowest T-score value for the BMD measured at the lumbar spine, total hip, or femoral neck, and like the Endocrine Society, also recommends the use of forearm measurements if the lumbar spine or hip scans cannot be used. ${ }^{41}$

The WHO and IOF recommend the use of the Third National Health and Nutrition Examination Survey (NHANES III) reference database for femoral neck measurements in white women aged 20-29 years when calculating T-scores in men. ${ }^{37}$ This position is currently supported by $\mathrm{NOGG}^{38}$ and Osteoporosis Canada, ${ }^{41}$ while the Endocrine Society ${ }^{40}$ recommends the use of male reference data for calculating T-scores in men. The International Society of 
Clinical Densitometry recently changed their official position to recommend the use of the female referent database when calculating T-scores in men. ${ }^{42}$

\section{Epidemiology of osteoporosis and fracture Prevalence of osteoporosis}

Osteoporosis remains largely underdiagnosed in males. The number of males with osteoporosis is not currently known, which is mainly due to the infrequency of screening and controversies in BMD testing standards in men. ${ }^{28} \mathrm{Using}$ the WHO diagnostic criteria, it is estimated that $1-2$ million men in the US have osteoporosis and an additional 8-13 million have osteopenia. ${ }^{28}$ Using data from 2002, researchers estimated that about $25 \%$ of the male Medicare population had osteoporosis. ${ }^{43}$ A recent study in Denmark using measured BMD on a sample of 600 men aged 60-74 years found that $10.2 \%$ had osteoporosis. ${ }^{44}$ A new comprehensive report estimates that 5.5 million men in the European Union (EU) had osteoporosis in 2010 based on the WHO diagnostic criterion. ${ }^{45}$ The overall prevalence of osteoporosis in men aged 50 years and older in the EU was $6.6 \%$, but the prevalence increased significantly with age, reaching $16.6 \%$ in men aged 80 years and older.

The main concern of osteoporosis is not just low BMD, but the occurrence of fractures. BMD values are only surrogate markers for fracture risk, and may not be completely correlated. BMD testing, such as using DXA, is a poor-tomoderate predictor of fracture. ${ }^{46}$ A Danish study showed that only $24 \%$ of patients that had a vertebral fracture had osteoporosis, whereas about $1.5 \%$ of patients with osteoporosis had a vertebral fracture. ${ }^{44}$

\section{Incidence of fractures}

In 2008, osteoporotic hip fractures in men resulted in approximately 109,000 emergency department visits in the $\mathrm{US}^{47}$ For men, the incidence of hip fractures ranged from 0.56 per 1,000 patients per year at age 60 years to 13 per 1,000 patients per year by age 85 years. These results were similar to those reported in Norway from 2004-2005, where there was an incidence of 0.49 hip fractures per 1,000 person years at age 60 years, which then increased sharply to 12.3 hip fractures per 1,000 person years by age 85 years. ${ }^{48}$ These estimates translate to about a $6 \%$ lifetime risk of hip fracture in men. ${ }^{47}$ Interestingly, for men of Asian descent, this incidence appears to be about half of that in Caucasians. ${ }^{49}$

Looking at changes over time in Norway, the incidence of hip fractures in men decreased from 1999 to 2008 by $4.8 \%$ (95\% confidence interval [CI]: 0.7-8.7). ${ }^{50}$ This decrease was accompanied by an even greater decrease (13.4\%) in hip fractures in women. In the US, there was a $16 \%$ increase in hip fractures from 1986 to 1995 , which was then followed by a decrease of $19.2 \%$ from 1995 to 2005 , resulting in a net decrease in hip fractures over the 20 -year period. ${ }^{51}$ In Canada, there has been a steady decline in the incidence of hip fractures, comparable to what was seen in the US. ${ }^{52}$ In Belgium, the incidence rate of hip fractures in men remained stable from 2000 to 2007, but substantially decreased for women. ${ }^{53}$ The study also showed a four-fold increase in anti-osteoporosis prescriptions in men, but the overall treatment numbers remained very low. Alternatively, in the Netherlands, the incidence of hip fractures in older men actually increased about $43 \%$ from 1981 to $2008,,^{54}$ and there was also a sharp increase in the incidence rate of vertebral fractures from 1986 to $2008 .{ }^{55}$ For men aged 70-74 years in this study, the incidence of vertebral fractures increased from 18.9 per 100,000 persons in 1986 to 1990 to 61.3 per 100,000 persons in 2006 to 2008 , while the age-adjusted incidence rate for emergency department visits due to vertebral fractures doubled. ${ }^{55}$ Seasonally, there appears to be an increase in the fracture risk during the winter months, most likely due to slips and falls on ice and snow. ${ }^{48}$

The risk of hip fractures increase substantially if there is a history of previous fragility fractures. After the first hip fracture, the risk of a subsequent hip fracture increases 4.6-fold (95\% CI: 4.5-4.7) in US men, ${ }^{50}$ and the incidence of a second hip fracture has not changed substantially over time. In Taiwanese males, the incidence of hip fractures is 3.6 times higher in patients that have had a previous distal radius fracture (1.40 per 1,000 person-years versus 5.07 per 1,000 person-years). ${ }^{56}$

Additionally, a Swedish study of men diagnosed with prostate cancer found that there was an additional 16 fractures per 1,000 patient years for patients treated with orchiectomy, and an extra 9.8 fractures per 1,000 patient years in patients treated with GnRH antagonists. In the study, the incidence of hip fractures doubled in men undergoing endocrine treatment. ${ }^{57}$ Subgroup analysis of males with low likelihood of metastases suggests that the increase in the fracture incidence was due to prostate cancer treatment, and not metastases alone. A similar increase in fracture risk due to prostate cancer was seen in the US in patients treated with androgen-deprivation therapy, where again, the risk of fractures nearly doubled. ${ }^{58}$

\section{Burden of disease}

While the age-adjusted incidence of fractures has decreased slightly in recent years, ${ }^{51,52}$ the number of people over 65 years is increasing, leading to an increase in the volume of fragility 
fractures and corresponding costs. We present several studies that estimate the economic burden of osteoporosis and fracture in North America and Europe. For ease of comparison, all costs have been converted into 2013 US dollars. US costs from other years were adjusted to 2013 values using the US Bureau of Labor Statistics Consumer Price Index (CPI $)^{59}$ and other currencies were converted to US dollars by using average yearly exchange rates from the International Monetary Fund $^{60}$ and then adjusting to 2013 US dollars using the CPI. The total cost of fragility fractures in the US is estimated at US\$15.8-23.2 billion per year, not including indirect costs such as lost productivity of patients and caregivers. ${ }^{61}$ Of the cost of fracture treatment, it is estimated that $70 \%$ is borne by Medicare, $17 \%$ by private insurers, $10 \%$ by patients, and the rest by Medicaid. ${ }^{43}$

One study showed that $5 \%$ of the Medicare population was treated for a fracture, which resulted in an annual incremental impact of US\$1,136 per patient (95\% CI: US\$8,288-13,983). This estimate implies an aggregate cost of fractures of US\$18.1 billion per year in the US. ${ }^{43}$ There was an additional US\$2.6 billion for the cost of osteoporosis-related physician visits and medications for patients that did not fracture, for a total of about US\$20.7 billion for osteoporosis costs in Medicare-eligible patients. Interestingly, fractures in women are estimated to cost an average of US\$1,683 less than fractures in men. ${ }^{43}$

In privately insured patients, the mean incremental direct cost per patient with nonvertebral fractures compared to control patients without fractures was US\$6,888 (US\$13,446 versus US\$6,558; $P<0.05$ ), of which, 35\% was composed of inpatient costs and $15 \%$ was composed of medication costs. ${ }^{62}$ In the same study, the cost to Medicare for nonvertebral fractures was US\$15,469 (US\$25,960 versus US\$10,491; $P<0.05$ ), of which, 51\% was inpatient, $24 \%$ long-term care, and 3\% medications. Medicare patients had higher costs in the study because they were more severely ill, older, and had higher medical resource use. Hip fractures were the most expensive fracture on a per-person basis, costing an additional US\$14,516 per patient per year for private insurance and US\$29,488 per patient per year for Medicare. ${ }^{62}$

For Medicaid, a study found that patients with osteoporosis without a fracture on average cost an extra US\$745 per year compared to non-osteoporotic patients. ${ }^{63}$ Those that did have a fracture had an increased cost of US $\$ 4,458$ per year. Again, hip fractures were the most expensive, with an incremental cost of US\$17,954. Additionally, three times the number of fracture patients received disability benefits, and the benefits lasted twice as long compared to those without fractures. ${ }^{63}$
The results were similar in Canada, where hip fractures account for $57.7 \%$ of all fracture-related hospital stays, costing about US\$21,516 per patient. ${ }^{64}$ Nationally, the costs for osteoporosis-related fractures in men resulted in an estimated US\$352 million for acute care costs, US\$34 million for physician visits, and US\$89 million in other care. Overall indirect costs were estimated to be about US\$85 million. ${ }^{64} \mathrm{In}$ the EU, direct osteoporosis costs in men aged 50 years and older were estimated at US\$16.4 billion and are expected to rise to US\$21.9 billion by $2025 . .^{45}$

In addition to health care costs, osteoporotic fractures can also lead to pain, disability, and diminished quality of life. When evaluating the impact on quality of life 1 year after a hip fracture, a systematic review showed a utility of $0.77-0.83$ (0 meaning death and 1 meaning perfect health) ${ }^{65}$ For vertebral fractures, the quality of life 1-year post-fracture was 0.72 .

\section{Osteoporosis screening Risk factors}

While the clinical diagnosis of osteoporosis is based on BMD T-scores, the use of clinical risk factors may help identify men at high risk of fracture to select for BMD testing. Several recent studies have focused on identifying risk factors associated with low BMD and fracture in men. The Osteoporotic Fractures in Men Study (MrOS) prospectively followed almost 6,000 elderly men and found that history of fracture after the age of 50 years, increased age, tricyclic antidepressant use, recent falls, depressed mood, and poor neuromuscular function were associated with an increased risk of nonvertebral fractures independent of BMD. ${ }^{66}$ Further, having three or more of these clinical risk factors was associated with a six-fold increase in the risk of a nonspine fracture. A 2012 systematic review and meta-analysis of risk factors for osteoporosisrelated fractures in men found that increased age, low body mass index (BMI), excessive alcohol consumption, current smoking, long-term corticosteroid use, history of prior fracture, history of falls in prior year, hypogonadism, stroke, and diabetes were significantly associated with an increased risk of fracture. ${ }^{67}$ Most of the identified risk factors were of low magnitude (adjusted odds ratios [OR] between 1 and 2), but prior fracture, history of falls, hypogonadism, and stroke were of a larger magnitude, with adjusted ORs greater than 2. Many of these factors are included in the screening guidelines and fracture risk algorithms that are discussed below.

\section{Screening guidelines}

Many organizations now provide guidance for osteoporosis screening in males. These guidelines are part of an integrated 
approach aimed at identifying males who should undergo diagnostic assessment using DXA in order to inform treatment decisions. Although screening guidelines vary by organization, most rely on age and the identification of other clinical risk factors to identify males at risk for fracture. In the US, the NOF ${ }^{39}$ the Endocrine Society, ${ }^{40}$ and the International Society for Clinical Densitometry ${ }^{68}$ guidelines are consistent in recommending a DXA scan for men aged 70 years and older and in younger men with prior fractures or other risk factors. The NOF guidelines recommend screening in men under the age of 70 years if they had glucocorticoid exposure or a prior fracture. ${ }^{39}$ The Endocrine Society recommends screening in males younger than 70 years if they have risk factors such as prior fracture as an adult, low body weight, and smoking ${ }^{40}$ and the International Society for Clinical Densitometry guidelines include prior fracture or disease or medication associated with bone loss or low BMD. ${ }^{68}$ Osteoporosis Canada recommends BMD screening for males aged 65 years and older, and in younger men with risk factors, including prior fracture, use of glucocorticoids or other high-risk medications, high alcohol intake, current smoking, and diseases associated with rapid bone loss, fracture, or osteoporosis. ${ }^{41}$ The NOGG 2013 guidelines recommend the assessment of the 10-year major osteoporotic fracture probability in men aged 50 years and older using the UK Fracture Risk Assessment Tool (FRAX), an absolute risk assessment tool, with BMD testing suggested based on age and fracture probability using predetermined assessment thresholds. ${ }^{38}$ Table 2 presents a summary of several North American and European screening guidelines.

It should be noted that not all agencies think osteoporosis screening in males is warranted at this time. The US Preventive Services Task Force concluded that there is currently not enough evidence to recommend widespread BMD screening in men based on the lack of studies examining the impact of screening on fracture rates or fracture-related morbidity and mortality and the lack of randomized trials of drug therapy on fracture prevention in men. ${ }^{69}$ Additionally, there is little research of the cost-effectiveness of bone densitometry screening in men although one study found that screening may be cost-effective in men aged 80 years and over and in males aged over 65 years who have experienced a prior fracture. ${ }^{70}$

\section{Absolute risk assessment}

Low BMD alone is a poor predictor of fracture in men, with one study finding that only $21 \%$ of elderly men who went on to have a nonvertebral fracture and $39 \%$ of men who

Table 2 Male osteoporosis screening guidelines

\begin{tabular}{|c|c|}
\hline Organization & Screening recommendations \\
\hline National Osteoporosis Foundation (NOF) ${ }^{39}$ & $\begin{array}{l}\text { BMD testing using DXA for men age } 70+\text { and in those age 50-69 with risk factors for fracture. In } \\
\text { those with a prior fracture, BMD testing and vertebral imaging are recommended to assess disease } \\
\text { severity. Vertebral imaging is recommended in men aged } 80 \text { years and older, in men aged } 75-79 \\
\text { years with a T-score of }-1.5 \text { or less, and in men aged } 50-69 \text { years with low trauma fracture, long- } \\
\text { term glucocorticoid treatment, historical height loss of at least I.5 inches, or prospective height } \\
\text { loss of } 0.8 \text { inches or more. }\end{array}$ \\
\hline The Endocrine Society ${ }^{40}$ & $\begin{array}{l}\text { BMD testing using DXA in men aged } 70 \text { years and older and in men aged } 50-69 \text { years who have } \\
\text { risk factors such as low body weight, prior fracture as an adult, and smoking. Laboratory testing } \\
\text { should be done to detect secondary causes. }\end{array}$ \\
\hline International Society for Clinical & BMD testing for men aged 70 years and older and in men under the age of 70 years with clinical risk \\
\hline Densitometry ${ }^{68,71}$ & factors including prior fracture or disease or medication associated with bone loss or low BMD. \\
\hline National Osteoporosis Guideline & Assess 10 -year major osteoporotic fracture probability in men aged 50 years and older using UK \\
\hline Group (NOGG) ${ }^{38}$ & $\begin{array}{l}\text { FRAX. BMD testing is recommended based on age and fracture probability using predetermined } \\
\text { assessment thresholds. }\end{array}$ \\
\hline Osteoporosis Canada ${ }^{41}$ & $\begin{array}{l}\text { BMD testing in men aged } 65 \text { years and older and in men aged 50-64 years with fragility fracture } \\
\text { after age } 40 \text { years, prolonged use of glucocorticoids, parental hip fracture, vertebral fracture } \\
\text { or osteopenia based on radiography, high alcohol intake, current smoking, low body weight or } \\
\text { major weight loss, and other disorders associated with osteoporosis. In men younger than } \\
50 \text { years, BMD testing is recommended for those with fragility fractures, use of high-risk } \\
\text { medications, hypogonadism, malabsorption, chronic inflammatory conditions, primary } \\
\text { hyperparathyroidism, or other conditions associated with bone loss or fracture. }\end{array}$ \\
\hline
\end{tabular}

Notes: Copyright (C) 2014. National Osteoporosis Foundation. Adapted with permission from Clinician's Guide to Prevention and Treatment of Osteoporosis. Washington, DC: National Osteoporosis Foundation; 2014. Available from: http://nof.org/hcp/clinicians-guide. Accessed April II, 20I4.39 Copyright @ C 20I0. CMA. Adapted from Papaioannou A, Morin S, Cheung AM, Atkinson S, Brown JP, Feldman S, Hanley DA, Hodsman A, Jamal SA, Kaiser SM, Kvern B, Siminoski K, Leslie WD; Scientific Advisory Council of Osteoporosis Canada. 2010 clinical practice guidelines for the diagnosis and management of osteoporosis in Canada: summary. CMAJ. 20I0; I82(I7):I864-1873. This work is protected by copyright and the making of this copy was with the permission of Access Copyright. Any alteration of its content or further copying in any form whatsoever is strictly prohibited unless otherwise permitted by law. ${ }^{41}$

Abbreviations: BMD, bone mineral density; DXA, dual-energy X-ray absorptiometry; FRAX, Fracture Risk Assessment Tool. 
went on to have a hip fracture had a T-score below $-2.5 .^{72}$ This indicates a need for tools that predict fracture risk independently of, or in addition to, BMD. ${ }^{72}$ The use of risk assessment tools that include clinically relevant risk factors to predict fracture risk are being increasingly incorporated into osteoporosis screening and treating guidelines.

The WHO FRAX (http://www.shef.ac.uk/FRAX/ index.aspx) has been incorporated into many national and international screening and treatment guidelines worldwide. FRAX is a computerized algorithm that calculates the 10 -year probability of hip fracture and the 10-year probability of a major osteoporotic fracture using clinical risk factors, with the optional inclusion of BMD. Risk factors included in FRAX are age, sex, weight, height, previous fracture, parental history of hip fracture, current smoking, secondary osteoporosis, glucocorticoid exposure, rheumatoid arthritis, three or more units of alcohol per day, and BMD at the femoral neck using DXA, if available. FRAX models currently exist for 53 countries and are calibrated to reflect country-specific epidemiology of fractures and mortality. ${ }^{73}$

Other absolute risk assessment algorithms include the Canadian Association of Radiologists and Osteoporosis Canada (CAROC) tool, Garvan nomogram, and Qfracture. These tools differ in the number of clinical risk factors included, but all incorporate age and sex. The CAROC, recommended for risk assessment by the Osteoporosis Canada guidelines, uses age, sex, and femoral neck T-score to determine initial 10-year absolute major fracture risk (low, moderate, or high) and adjusts risk upward in the presence of prolonged glucocorticoid use or fragility fractures after the age of 40 years. ${ }^{41}$ A patient with both of these risk adjustments is classified as high risk irrespective of BMD. The Garvan nomogram was developed in Australia to predict hip or major osteoporotic fracture using age, sex, history of prior fractures, and femoral neck BMD or weight (if BMD unavailable). ${ }^{74}$ Qfracture was developed for use in the UK and uses 31 risk factors to calculate the 10-year probability of osteoporotic fracture or hip fracture, but does not include BMD as an input. ${ }^{75}$

The performance of these tools has not been extensively studied in a male population. A study that evaluated the predictive performance of the Garvan nomogram and FRAX in a sample of Australian men in a clinical setting found that FRAX discriminates fracture risk poorly, but the number of men studied was small. ${ }^{76} \mathrm{~A}$ validation study of the Canadian FRAX concluded that the model was well-calibrated and adequately discriminates hip fracture in men. ${ }^{77}$ In an observational study of FRAX calibration and discrimination in the MrOS cohort, the tool showed fairly accurate predicted risk for hip fractures without BMD but did not predict the risk of major osteoporotic fractures as well. ${ }^{78}$ The discrimination of the tool was poor for major osteoporotic fractures with or without the inclusion of BMD, but was fair for hip fracture with the inclusion of BMD. These limited results highlight the need for further research into the development and validation of fracture risk assessment tools in men. One example of a recently developed model in a male cohort was that by LaFleur et $\mathrm{al}^{79}$ to estimate absolute fracture risk in a regional cohort of male veterans using data collected passively in routine health care operations. The algorithm predicted absolute risk of hip or any major fracture using age, BMI, smoking, alcohol use, fall risk, number of clinic visits, and several comorbid diseases and drug exposures, and showed good to acceptable discrimination for hip fracture and any major fracture, respectively.

\section{Treatment Whom to treat}

Treatment guidelines for male osteoporosis rely on the results of BMD screening and the presence of clinical risk factors to select those at high risk for fracture to treat with pharmacologic therapies. Table 3 presents the NOF, Endocrine Society, NOGG, and Osteoporosis Canada guidelines for treating male osteoporosis. All of these agencies incorporate the use of an absolute risk assessment tool, such as FRAX, into their treatment guidelines. The NOF and Endocrine Society both recommend treatment in males over the age of 50 years with a prior fracture, in those with a T-score indicative of osteoporosis based on BMD testing, and in osteopenic men with a 10 -year probability of a hip fracture $\geq 3 \%$ or a 10 -year probability of a major fracture $\geq 20 \%$ based on the US-adapted FRAX. ${ }^{39,40}$ Osteoporosis Canada recommends treatment in men over the age of 50 years with a previous hip or spine fracture, or multiple fragility fractures, irrespective of BMD. ${ }^{41}$ Fracture risk assessment using the CAROC Risk Assessment tool, or Canadian FRAX, is also recommended to classify patients as low, moderate, or high risk..$^{41}$ Treatment is recommended in men at high risk of fracture defined as a 10 -year major fracture risk $>10 \%$; in men with moderate fracture risk, treatment should be considered in the presence of selected risk factors (Table 3 ).

In the absence of a prior fragility fracture, the NOF and Endocrine Society treatment guidelines rely on T-scores from DXA scanning as the first approach to identify males for treatment. The NOGG guidelines differ in that treatment for men may be recommended based solely on clinical risk factors in the absence of a BMD test if the probability of fracture lies above a pre-determined upper assessment threshold. 
Table 3 Osteoporosis treatment guidelines for males

\begin{tabular}{|c|c|}
\hline Organization & Pharmacological treatment recommendations \\
\hline National Osteoporosis Foundation (NOF) ${ }^{39}$ & $\begin{array}{l}\text { Treatment recommended for men aged } 50 \text { years and older with hip or vertebral fracture (clinical or } \\
\text { on imaging); T-score less than }-2.5 \text { at femoral neck, total hip, or lumbar spine; T-score between }-1.0 \\
\text { and }-2.5 \text { at the femoral neck or lumbar spine; and a } 10 \text {-year probability of a hip fracture } \geq 3 \% \text { or a } \\
\text { I0-year probability of a major fracture } \geq 20 \% \text { based on the US-adapted FRAX. }\end{array}$ \\
\hline The Endocrine Society ${ }^{40}$ & $\begin{array}{l}\text { Recommend treatment in men who had hip or vertebral fracture without major trauma; BMD } \\
\text { of spine, femoral neck, or total hip } 2.5 \text { SD or more below mean of normal young males; T-score } \\
\text { between }-1.0 \text { and }-2.5 \text { at the femoral neck or lumbar spine plus a } 10 \text {-year probability of a hip fracture } \\
\geq 3 \% \text { or a } 10 \text {-year probability of a major fracture } \geq 20 \% \text { based on FRAX. Treatment is also suggested } \\
\text { in men aged } 50 \text { years and older receiving long-term glucocorticoid therapy (equivalent to } 7.5 \mathrm{mg} \text { or } \\
\text { greater of prednisone for } 3 \text { months) as recommended in the } 2010 \text { guidelines of the American Society } \\
\text { of Rheumatology. }{ }^{80}\end{array}$ \\
\hline Osteoporosis Canada ${ }^{41}$ & $\begin{array}{l}\text { Assess fracture risk using CAROC or Canadian FRAX. Recommend treatment for high-risk men } \\
\text { with } 10 \text {-year fracture risk }>20 \% \text {, prior hip or spine fracture, or multiple prior fractures. In men with } \\
\text { moderate fracture risk ( } 10 \text {-year risk between } 10 \% \text { and } 20 \% \text { ), consider treatment for those with the } \\
\text { following risk factors: vertebral fracture identified by imaging, previous wrist fracture in those over the } \\
\text { age of } 65 \text { years or with T-score less than or equal to }-2.5 \text {, lumbar spine T-score much smaller than } \\
\text { femoral neck T-score, androgen-deprivation therapy for prostate cancer, long-term glucocorticoid } \\
\text { use, recurrent falls, or other disorders associated with osteoporosis, bone, loss, or fractures. }\end{array}$ \\
\hline National Osteoporosis Guideline & Assess 10-year osteoporotic fracture probability in men aged 50 years or older using UK FRAX. \\
\hline Group (NOGG) ${ }^{38}$ & Treatment thresholds both with and without BMD testing are based on age and fracture probability. \\
\hline
\end{tabular}

Notes: Copyright (c) 2010. CMA. Adapted from Papaioannou A, Morin S, Cheung AM, Atkinson S, Brown JP, Feldman S, Hanley DA, Hodsman A, Jamal SA, Kaiser SM, Kvern B, Siminoski K, Leslie WD; Scientific Advisory Council of Osteoporosis Canada. 2010 clinical practice guidelines for the diagnosis and management of osteoporosis in Canada: summary. CMAJ. 2010;182(17):1864-1873. This work is protected by copyright and the making of this copy was with the permission of Access Copyright. Any alteration of its content or further copying in any form whatsoever is strictly prohibited unless otherwise permitted by law. ${ }^{4}$

Abbreviations: BMD, bone mineral density; CAROC, Canadian Association of Radiologists and Osteoporosis Canada; FRAX, Fracture Risk Assessment Tool; SD, standard deviation.

\section{Nonpharmacologic treatment}

Nonpharmacologic approaches for the prevention and treatment of osteoporosis in men include diet and lifestyle changes to reduce modifiable fracture risks. These approaches are incorporated into many osteoporosis clinical guidelines. For example, the NOF, ${ }^{39}$ Endocrine Society, ${ }^{40}$ and Osteoporosis Canada $^{41}$ all recommend adequate calcium and vitamin D intake and encourage regular weight-bearing and musclestrengthening physical activity. The NOF and Endocrine Society also advocate tobacco cessation and the avoidance of excessive alcohol. Fall prevention strategies are recommended by Osteoporosis Canada and the NOF. The NOF and Osteoporosis Canada guidelines are universal recommendations applicable to all men aged 50 years and older while the Endocrine Society guidelines apply to men with or at risk for osteoporosis. The $\mathrm{NOGG}^{38}$ does not make any population-based recommendations, but does advise that general osteoporosis management should include the correction of calcium and vitamin D deficiencies, assessment of fall risks, and mobility maintenance.

The evidence surrounding the anti-fracture efficacy of these interventions in males is varied. While current smoking and consumption of ten or more alcoholic drinks per week are associated with moderately increased risk of fracture, the effects of smoking cessation and alcohol reduction have been less frequently studied. ${ }^{67}$ One observational study in men showed that former smokers had a lower fracture risk than current smokers (although still a higher risk than never smokers) and the effect was longlasting. ${ }^{81}$ The Framingham study demonstrated no significant change in hip fracture risk after decreasing alcohol consumption from heavy to light levels. ${ }^{82}$ The evidence supporting calcium and vitamin D supplementation and physical activity is also mixed. A recent systematic review found that the effect of calcium intake on fracture outcomes in men was inconsistent, but there was substantial heterogeneity in how calcium intake was defined and assessed ${ }^{67}$ Concerning vitamin $\mathrm{D}$, a systematic review and meta-analysis found that daily supplementation with 700-800 IU of oral vitamin D was associated with decreased hip and nonvertebral fractures. ${ }^{83}$ This study did not find any difference in effect between males and females, but the data on males were limited. Another recent systematic review of exercise interventions on fall-related fractures in patients with osteopenia or osteoporosis concluded that these interventions may reduce falls and fall-related fractures; however, most of these studies did not directly assess fall or fracture outcomes and the majority were conducted in postmenopausal females. ${ }^{84}$

\section{Pharmacologic treatment}

The US Food and Drug Administration (FDA)-approved pharmacologic therapies for osteoporosis treatment in men include teriparatide, denosumab, and the bisphosphonates 
alendronate, risedronate, and zoledronic acid. In the EU, strontium ranelate is also approved for the treatment of male osteoporosis along with teriparatide and alendronate, risedronate, and zoledronic acid. All of these agents inhibit bone resorption, except teriparatide, which promotes new bone growth.

The anti-fracture efficacy of these drugs has mostly been studied in postmenopausal women. ${ }^{39,85}$ Large randomized controlled trials of osteoporosis treatments with a fracture endpoint are rare in men; studies in men tend to be small with changes in BMD or bone turnover markers as the primary outcome, with fracture incidence usually reported as a secondary outcome. ${ }^{40}$ The use of surrogate markers in these studies is justified on the basis of therapeutic equivalence; if the changes in BMD in men on a given treatment are similar to those observed in women on that treatment over the same duration, then it is assumed that fractures endpoints will also be similar. ${ }^{35}$ However, due to gender differences in bone development, pathophysiology, and risk factors, it is unclear if the anti-fracture benefits seen in women are the same in men. ${ }^{86}$ Further, there is little evidence surrounding the comparative effectiveness of the various osteoporosis treatments, as recent systematic reviews of treatments to prevent osteoporotic fractures found few studies that examined the effect of osteoporosis treatments on fracture prevention in men and no large trials that compared treatments head-to-head. ${ }^{86-88}$

Bisphosphonates, most commonly generic alendronate, are often prescribed as the first-line treatment to prevent fracture. Alendronate ${ }^{89}$ risedronate, ${ }^{90}$ and zoledronic acid ${ }^{91}$ have been shown to reduce the risk of vertebral fracture in men. Risedronate has also demonstrated reductions in the incidence of nonvertebral ${ }^{90}$ and hip ${ }^{92}$ fractures in men. However, there is an overall lack of evidence concerning the effectiveness of bisphosphonates for reducing hip and other nonvertebral fractures in osteoporotic men.

The parathyroid hormone teriparatide is the only anabolic agent that is FDA-approved for the treatment of severe or glucocorticoid-induced osteoporosis in men. ${ }^{93}$ Teriparatide

Table 4 Summary of research needs in male osteoporosis

\begin{tabular}{ll}
\hline Area & Research needs \\
\hline Screening & $\begin{array}{l}\text { Impact of screening on fracture rates and } \\
\text { fracture-related outcomes } \\
\text { Cost-effectiveness of bone densitometry in men } \\
\text { Development and validation of fracture risk } \\
\text { Risk assessment }\end{array}$ \\
Treatment & $\begin{array}{l}\text { Effectiveness of osteoporosis treatment in } \\
\text { reducing hip and nonvertebral fractures in men } \\
\text { Comparative effectiveness of osteoporosis } \\
\text { treatments in men }\end{array}$ \\
\hline
\end{tabular}

has been shown to significantly decrease the incidence of vertebral fractures. ${ }^{94}$ Treatment with teriparatide is controversial due to possible side effects and is not recommended for durations longer than 2 years. ${ }^{85}$

Denosumab, recently FDA-approved for treating male osteoporosis, was shown to significantly increase BMD at the lumbar spine, total hip, femoral neck, trochanter, and $1 / 3$ radius in men with low bone density. ${ }^{95}$ In men receiving androgen deprivation therapy for prostate cancer, denosumab was associated with a decreased incidence of new vertebral fractures. ${ }^{96}$ In men with osteoporosis, strontium ranelate increased BMD at the lumbar spine, femoral neck, and total hip, which is consistent with the effects seen in women. ${ }^{97}$

\section{Conclusion}

Male osteoporosis remains underdiagnosed and under-treated, but is increasingly recognized as a significant public health concern. Osteoporotic fractures lead to considerable personal and societal costs as a result of increased morbidity and mortality. There is now more knowledge of the secondary causes of osteoporosis in men and the risk factors for osteoporosis and fracture in the male population. Many organizations now provide clinical guidelines to address osteoporosis screening and treatment in men. This is hopefully an important step towards improved diagnosis and treatment, although opportunities for further research remain (Table 4). Absolute risk assessment tools such as the FRAX may play an important role in identifying men at risk for fracture, although more research is needed in developing and validating these tools in male populations. The approved pharmacological treatments have shown reduced vertebral fracture incidence in men, but there remains an evidence gap concerning the effectiveness of these treatments in reducing hip and nonvertebral fractures. More research is needed to address this gap and to examine the comparative effectiveness of the various osteoporosis treatments.

\section{Disclosure}

The authors report no conflicts of interest in this work.

\section{References}

1. Becker DJ, Kilgore ML, Morrisey MA. The societal burden of osteoporosis. Curr Rheumatol Rep. 2010;12(3):186-191.

2. National Osteoporosis Foundation [webpage on the Internet]. Just for Men. Available at: http://nof.org/articles/236. Accessed September 30, 2013.

3. Johnell O, Kanis JA. An estimate of the worldwide prevalence and disability associated with osteoporotic fractures. Osteoporos Int. 2006;17(12):1726-1733.

4. Burge R, Dawson-Hughes B, Solomon DH, Wong JB, King A, Tosteson A. Incidence and economic burden of osteoporosis-related fractures in the United States, 2005-2025. J Bone Miner Res. 2007;22(3): 465-475. 
5. von Friesendorff M, McGuigan FE, Besjakov J, Akesson K. Hip fracture in men-survival and subsequent fractures: a cohort study with 22-year follow-up. J Am Geriatr Soc. 2011;59(5):806-813.

6. Bonjour JP, Theintz G, Law F, Slosman D, Rizzoli R. Peak bone mass. Osteoporos Int. 1994;4 Suppl 1:7-13.

7. Lambert JK, Zaidi M, Mechanick JI. Male osteoporosis: epidemiology and the pathogenesis of aging bones. Curr Osteoporos Rep. 2011;9(4): 229-236.

8. Seeman E. Growth in bone mass and size - are racial and gender differences in bone mineral density more apparent than real? J Clin Endocrinol Metab. 1998;83(5):1414-1419.

9. Karsenty G. The mutual dependence between bone and gonads. $J$ Endocrinol. 2012;213(2):107-114.

10. Riggs BL, Khosla S, Melton LJ 3rd. Sex steroids and the construction and conservation of the adult skeleton. Endocr Rev. 2002;23(3): 279-302.

11. De Oliveira DH, Fighera TM, Bianchet LC, Kulak CA, Kulak J. Androgens and bone. Minerva Endocrinol. 2012;37(4):305-314.

12. Looker AC, Beck TJ, Orwoll ES. Does body size account for gender differences in femur bone density and geometry? J Bone Miner Res. 2001;16(7):1291-1299.

13. Vandewalle S, Taes Y, Van Helvoirt M, et al. Bone size and bone strength are increased in obese male adolescents. J Clin Endocrinol Metab. 2013;98(7):3019-3028.

14. Heidemann M, Mølgaard C, Husby S, et al. The intensity of physical activity influences bone mineral accrual in childhood: the childhood health, activity and motor performance school (the CHAMPS) study, Denmark. BMC Pediatr. 2013;13:32.

15. Duan Y, Beck TJ, Wang XF, Seeman E. Structural and biomechanical basis of sexual dimorphism in femoral neck fragility has its origins in growth and aging. J Bone Miner Res. 2003;18(10):1766-1774.

16. Seeman $E$. The structural and biomechanical basis of the gain and loss of bone strength in women and men. Endocrinol Metab Clin North Am. 2003;32(1):25-38.

17. Gennari L, Bilezikian JP. Idiopathic osteoporosis in men. Curr Osteoporos Rep. 2013;11(4):286-298.

18. Gennari L, Brandi ML. Genetics of male osteoporosis. Calcif Tissue Int. 2001;69(4):200-204.

19. Cohen-Solal ME, Baudoin C, Omouri M, Kuntz D, De Vernejoul MC. Bone mass in middle-aged osteoporotic men and their relatives: familial effect. J Bone Miner Res. 1998;13(12):1909-1914.

20. Van Pottelbergh I, Goemaere S, Zmierczak H, De Bacquer D, Kaufman JM. Deficient acquisition of bone during maturation underlies idiopathic osteoporosis in men: evidence from a three-generation family study. J Bone Miner Res. 2003;18(2):303-311.

21. Silva DR, Coelho AC, Dumke A, et al. Osteoporosis prevalence and associated factors in patients with COPD: a cross-sectional study. Respir Care. 2011;56(7):961-968.

22. Morden NE, Sullivan SD, Bartle B, Lee TA. Skeletal health in men with chronic lung disease: rates of testing, treatment, and fractures. Osteoporos Int. 2011;22(6):1855-1862.

23. Shen C, Deng J, Zhou R, et al. Relation between bone mineral density, bone loss and the risk of cardiovascular disease in a Chinese cohort. Am J Cardiol. 2012;110(8):1138-1142.

24. Roux C. Osteoporosis in inflammatory joint diseases. Osteoporos Int. 2011;22(2):421-433.

25. Castaño-Betancourt MC, Rivadeneira F, Bierma-Zeinstra S, et al. Bone parameters across different types of hip osteoarthritis and their relationship to osteoporotic fracture risk. Arthritis Rheum. 2013;65(3): 693-700.

26. Hearn AP, Silber E. Osteoporosis in multiple sclerosis. Mult Scler. 2010;16(9):1031-1043.

27. Bazelier MT, de Vries F, Bentzen J, et al. Incidence of fractures in patients with multiple sclerosis: the Danish National Health Registers. Mult Scler. 2012;18(5):622-627.

28. Gennari L, Bilezikian JP. Osteoporosis in men. Endocrinol Metab Clin North Am. 2007;36(2):399-419.
29. Nelson RE, Nebeker JR, Sauer BC, LaFleur J. Factors associated with screening or treatment initiation among male United States veterans at risk for osteoporosis fracture. Bone. 2012;50(4):983-988.

30. Gielen E, Vanderschueren D, Callewaert F, Boonen S. Osteoporosis in men. Best Pract Res Clin Endocrinol Metab. 2011;25(2):321-335.

31. Khosla S, Amin S, Orwoll E. Osteoporosis in men. Endocr Rev. 2008;29(4):441-464.

32. Mosekilde L, Vestergaard P, Rejnmark L. The pathogenesis, treatment and prevention of osteoporosis in men. Drugs. 2013;73(1):15-29.

33. Kanis JA, Melton LJ 3rd, Christiansen C, Johnston CC, Khaltaev N. The diagnosis of osteoporosis. J Bone Miner Res. 1994;9(8):1137-1141.

34. Faulkner KG, Orwoll E. Implications in the use of T-scores for the diagnosis of osteoporosis in men. J Clin Densitom. 2002;5(1):87-93.

35. Kanis JA, Bianchi G, Bilezikian JP, et al. Towards a diagnostic and therapeutic consensus in male osteoporosis. Osteoporos Int. 2011;22(11): 2789-2798.

36. Brunader R, Shelton DK. Radiologic bone assessment in the evaluation of osteoporosis. Am Fam Physician. 2002;65(7):1357-1364.

37. Kanis JA, McCloskey EV, Johansson H, Oden A, Melton LJ 3rd, Khaltaev N. A reference standard for the description of osteoporosis. Bone. 2008;42(3):467-475.

38. Compston J, Bowring C, Cooper A, et al; National Osteoporosis Guideline Group. Diagnosis and management of osteoporosis in postmenopausal women and older men in the UK: National Osteoporosis Guideline Group (NOGG) update 2013. Maturitas. 2013;75(4):392-396.

39. National Osteoporosis Foundation. Clinician's Guide to Prevention and Treatment of Osteoporosis. Washington, DC: National Osteoporosis Foundation; 2014. Available from: http://nof.org/hcp/clinicians-guide. Accessed April 11, 2014.

40. Watts NB, Adler RA, Bilezikian JP, et al; Endocrine Society. Osteoporosis in men: an Endocrine Society clinical practice guideline. J Clin Endocrinol Metab. 2012;97(6):1802-1822.

41. Papaioannou A, Morin S, Cheung AM, et al; Scientific Advisory Council of Osteoporosis Canada. 2010 clinical practice guidelines for the diagnosis and management of osteoporosis in Canada: summary. CMAJ. 2010;182(17):1864-1873.

42. Watts NB, Leslie WD, Foldes AJ, Miller PD. 2013 International Society for Clinical Densitometry Position Development Conference: Task Force on Normative Databases. J Clin Densitom. 2013;16(4):472-481.

43. Blume SW, Curtis JR. Medical costs of osteoporosis in the elderly Medicare population. Osteoporos Int. 2011;22(6):1835-1844.

44. Frost M, Wraae K, Abrahamsen B, et al. Osteoporosis and vertebral fractures in men aged 60-74 years. Age Ageing. 2012;41(2):171-177.

45. Hernlund $\mathrm{E}$, Svedbom $\mathrm{A}$, Ivergård $\mathrm{M}$, et al. Osteoporosis in the European Union: medical management, epidemiology and economic burden. A report prepared in collaboration with the International Osteoporosis Foundation (IOF) and the European Federation of Pharmaceutical Industry Associations (EFPIA). Arch Osteoporos. 2013;8(1-2):136.

46. Nelson HD, Haney EM, Dana T, Bougatsos C, Chou R. Screening for osteoporosis: an update for the US. Preventive Services Task Force. Ann Intern Med. 2010;153(2):99-111.

47. Kim SH, Meehan JP, Blumenfeld T, Szabo RM. Hip fractures in the United States: 2008 nationwide emergency department sample. Arthritis Care Res (Hoboken). 2012;64(5):751-757.

48. Diamantopoulos AP, Rohde G, Johnsrud I, et al. Incidence rates of fragility hip fracture in middle-aged and elderly men and women in southern Norway. Age Ageing. 2012;41(1):86-92.

49. Bow CH, Cheung E, Cheung CL, et al. Ethnic difference of clinical vertebral fracture risk. Osteoporos Int. 2012;23(3):879-885.

50. Omsland TK, Holvik K, Meyer HE, et al. Hip fractures in Norway 1999-2008: time trends in total incidence and second hip fracture rates: a NOREPOS study. Eur J Epidemiol. 2012;27(10):807-814.

51. Brauer CA, Coca-Perraillon M, Cutler DM, Rosen AB. Incidence and mortality of hip fractures in the United States. JAMA. 2009;302(14): 1573-1579. 
52. Leslie WD, O’Donnell S, Jean S, et al; Osteoporosis Surveillance Expert Working Group. Trends in hip fracture rates in Canada. JAMA. 2009;302(8):883-889.

53. Hiligsmann M, Bruyère $\mathrm{O}$, Roberfroid $\mathrm{D}$, et al. Trends in hip fracture incidence and in the prescription of antiosteoporosis medications during the same time period in Belgium (2000-2007). Arthritis Care Res (Hoboken). 2012;64(5):744-750.

54. Hartholt KA, Oudshoorn C, Zielinski SM, et al. The epidemic of hip fractures: are we on the right track? PLoS One. 2011;6(7):e22227.

55. Oudshoorn C, Hartholt KA, Zillikens MC, et al. Emergency department visits due to vertebral fractures in The Netherlands, 1986-2008 steep increase in the oldest old, strong association with falls. Injury. 2012;43(4):458-461.

56. Chen CW, Huang TL, Su LT, et al. Incidence of subsequent hip fractures is significantly increased within the first month after distal radius fracture in patients older than 60 years. J Trauma Acute Care Surg. 2013;74(1):317-321.

57. Thorstenson $\mathrm{A}$, Bratt $\mathrm{O}$, Akre $\mathrm{O}$, et al. Incidence of fractures causing hospitalisation in prostate cancer patients: results from the populationbased PCBaSe Sweden. Eur J Cancer. 2012;48(11):1672-1681.

58. Melton LJ 3rd, Lieber MM, Atkinson EJ, et al. Fracture risk in men with prostate cancer: a population-based study. J Bone Miner Res. 2011;26(8):1808-1815.

59. United States Bureau of Labor Statistics [webpage on the Internet] Consumer Price Index - All Urban Consumers. Available at: http:// www.bls.gov/cpi/data.htm. Accessed March 25, 2014.

60. International Monetary Fund [webpage on the Internet]. Exchange Rate Data. Available at: http://www.imf.org/external/data.htm. Accessed March 24, 2014.

61. Office of the Surgeon General (US). Bone Health and Osteoporosis: A Report of the Surgeon General. Rockville, MD: US Department of Health and Human Services; 2004.

62. Pike C, Birnbaum HG, Schiller M, Sharma H, Burge R, Edgell ET. Direct and indirect costs of non-vertebral fracture patients with osteoporosis in the US. Pharmacoeconomics. 2010;28(5): 395-409.

63. Rousculp MD, Long SR, Wang S, Schoenfeld MJ, Meadows ES. Economic burden of osteoporosis-related fractures in Medicaid. Value Health. 2007;10(2):144-152.

64. Tarride JE, Guo N, Hopkins R, et al. The burden of illness of osteoporosis in Canadian men. J Bone Miner Res. 2012;27(8): 1830-1838.

65. Hiligsmann M, Ethgen O, Richy F, Reginster JY. Utility values associated with osteoporotic fracture: a systematic review of the literature. Calcif Tissue Int. 2008;82(4):288-292.

66. Lewis CE, Ewing SK, Taylor BC, et al; Osteoporotic Fractures in Men (MrOS) Study Research Group. Predictors of non-spine fracture in elderly men: the MrOS study. J Bone Miner Res. 2007;22(2):211-219.

67. Drake MT, Murad MH, Mauck KF, et al. Clinical review. Risk factors for low bone mass-related fractures in men: a systematic review and meta-analysis. J Clin Endocrinol Metab. 2012;97(6): 1861-1870.

68. Lewiecki EM, Gordon CM, Baim S, et al. International Society for Clinical Densitometry 2007 Adult and Pediatric Official Positions. Bone. 2008;43(6):1115-1121.

69. US Preventive Services Task Force. Screening for osteoporosis: US preventive services task force recommendation statement. Ann Intern Med. 2011;154(5):356-364.

70. Schousboe JT, Taylor BC, Fink HA, et al. COst-effectiveness of bone densitometry followed by treatment of osteoporosis in older men. JAMA. 2007;298(6):629-637.

71. Malabanan AO, Rosen HN, Vokes TJ, et al. Indications of DXA in women younger than $65 \mathrm{yr}$ and men younger than $70 \mathrm{yr}$ : the 2013 Official Positions. J Clin Densitom. 2013;16(4):467-471.

72. Schuit SC, van der Klift M, Weel AE, et al. Fracture incidence and association with bone mineral density in elderly men and women: the Rotterdam Study. Bone. 2004;34(1):195-202.
73. Kanis JA, Johansson H, Oden A, Cooper C, McCloskey EV; Epidemiology and Quality of Life Working Group of IOF. Worldwide uptake of FRAX. Arch Osteoporos. 2014;9(1):166.

74. Nguyen ND, Frost SA, Center JR, Eisman JA, Nguyen TV. Development of prognostic nomograms for individualizing 5-year and 10-year fracture risks. Osteoporos Int. 2008;19(10):1431-1444.

75. Hippisley-Cox J, Coupland C. Derivation and validation of updated QFracture algorithm to predict risk of osteoporotic fracture in primary care in the United Kingdom: prospective open cohort study. BMJ. 2012;344:e3427.

76. Sandhu SK, Nguyen ND, Center JR, Pocock NA, Eisman JA, Nguyen TV. Prognosis of fracture: evaluation of predictive accuracy of the FRAX algorithm and Garvan nomogram. Osteoporos Int. 2010;21(5): 863-871.

77. Leslie WD, Lix LM, Johansson H, Oden A, McCloskey E, Kanis JA; Manitoba Bone Density Program. Independent clinical validation of a Canadian FRAX tool: fracture prediction and model calibration. J Bone Miner Res. 2010;25(11):2350-2358.

78. Ettinger B, Ensrud KE, Blackwell T, Curtis JR, Lapidus JA, Orwoll ES; Osteoporotic Fracture in Men (MrOS) Study Research Group. Performance of FRAX in a cohort of community-dwelling, ambulatory older men: the Osteoporotic Fractures in Men (MrOS) study. Osteoporos Int. 2013;24(4):1185-1193.

79. LaFleur J, Nelson RE, Yao Y, Adler RA, Nebeker JR. Validated risk rule using computerized data to identify males at high risk for fracture. Osteoporos Int. 2012;23(3):1017-1027.

80. Grossman JM, Gordon R, Ranganath VK, et al. American College of Rheumatology 2010 recommendations for the prevention and treatment of glucocorticoid-induced osteoporosis. Arthritis Care Res (Hoboken). 2010;62(11):1515-1526.

81. Olofsson H, Byberg L, Mohsen R, Melhus H, Lithell H, Michaëlsson K. Smoking and the risk of fracture in older men. J Bone Miner Res. 2005;20(7):1208-1215.

82. Felson DT, Kiel DP, Anderson JJ, Kannel WB. Alcohol consumption and hip fractures: the Framingham Study. Am J Epidemiol. 1988;128(5):1102-1110

83. Bischoff-Ferrari HA, Willett WC, Wong JB, Giovannucci E, Dietrich T, Dawson-Hughes B. Fracture prevention with vitamin D supplementation: a meta-analysis of randomized controlled trials JAMA. 2005;293(18):2257-2264.

84. de Kam D, Smulders E, Weerdesteyn V, Smits-Engelsman BC. Exercise interventions to reduce fall-related fractures and their risk factors in individuals with low bone density: a systematic review of randomized controlled trials. Osteoporos Int. 2009;20(12) 2111-2125.

85. Herrera A, Lobo-Escolar A, Mateo J, Gil J, Ibarz E, Gracia L. Male osteoporosis: a review. World J Orthop. 2012;3(12):223-234.

86. Schwarz P, Jorgensen NR, Mosekilde L, Vestergaard P. The evidence for efficacy of osteoporosis treatment in men with primary osteoporosis: a systematic review and meta-analysis of antiresorptive and anabolic treatment in men. J Osteoporos. 2011;2011:259818.

87. MacLean C, Newberry S, Maglione M, et al. Systematic review: comparative effectiveness of treatments to prevent fractures in men and women with low bone density or osteoporosis. Ann Intern Med. 2008;148(3):197-213.

88. Murad MH, Drake MT, Mullan RJ, et al. Clinical review. Comparative effectiveness of drug treatments to prevent fragility fractures: a systematic review and network meta-analysis. J Clin Endocrinol Metab. 2012;97(6):1871-1880.

89. Orwoll E, Ettinger M, Weiss S, et al. Alendronate for the treatment of osteoporosis in men. N Engl J Med. 2000;343(9):604-610.

90. Sato Y, Iwamoto J, Kanoko T, Satoh K. Risedronate sodium therapy for prevention of hip fracture in men 65 years or older after stroke. Arch Intern Med. 2005;165(15):1743-1748.

91. Boonen S, Reginster JY, Kaufman JM, et al. Fracture risk and zoledronic acid therapy in men with osteoporosis. N Engl J Med. 2012;367(18): 1714-1723. 
92. Ringe JD, Farahmand P, Faber H, Dorst A. Sustained efficacy of risedronate in men with primary and secondary osteoporosis: results of a 2-year study. Rheumatol Int. 2009;29(3):311-315.

93. Adler RA. Osteoporosis in men: recent progress. Endocrine. 2013;44(1): 40-46.

94. Kaufman JM, Orwoll E, Goemaere S, et al. Teriparatide effects on vertebral fractures and bone mineral density in men with osteoporosis: treatment and discontinuation of therapy. Osteoporos Int. 2005;16(5):510-516.

95. Orwoll E, Teglbjærg CS, Langdahl BL, et al. A randomized, placebocontrolled study of the effects of denosumab for the treatment of men with low bone mineral density. J Clin Endocrinol Metab. 2012;97(9): 3161-3169.
96. Smith MR, Egerdie B, Hernández Toriz N, et al; Denosumab HALT Prostate Cancer Study Group. Denosumab in men receiving androgendeprivation therapy for prostate cancer. $N$ Engl J Med. 2009;361(8): 745-755.

97. Kaufman JM, Audran M, Bianchi G, et al. Efficacy and safety of strontium ranelate in the treatment of osteoporosis in men. J Clin Endocrinol Metab. 2013;98(2):592-601.

\section{Publish your work in this journal}

Clinical Epidemiology is an international, peer-reviewed, open access journal focusing on disease and drug epidemiology, identification of risk factors and screening procedures to develop optimal preventative initiatives and programs. Specific topics include: diagnosis, prognosis, treatment, screening, prevention, risk factor modification, systematic

Submit your manuscript here: http://www.dovepress.com/clinical-epidemiology-journal

\section{Dovepress}

reviews, risk \& safety of medical interventions, epidemiology \& biostatical methods, evaluation of guidelines, translational medicine, health policies \& economic evaluations. The manuscript management system is completely online and includes a very quick and fair peer-review system, which is all easy to use. 